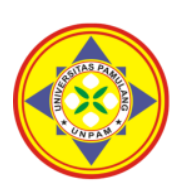

\title{
PENGARUH DISIPLIN KERJA DAN MOTIVASI TERHADAP KINERJA KARYAWAN PADA LUBANA SENGKOL WISATA PEMANCINGAN KELUARGA DI SERPONG TANGERANG SELATAN
}

\author{
${ }^{1 *}$ Nopi Oktavianti, ${ }^{2}$ Catur Galuh Ratnagung, ${ }^{3}$ Devi Fitria Wilandari \\ Universitas Pamulang, Tangerang Selatan, Banten, Indonesia \\ *dosen02481@unpam.ac.id
}

\begin{abstract}
Abstrak
Penelitian ini bertujuan untuk mengetahui pengaruh disiplin kerja dan motivasi terhadap kinerja karyawan pada Lubana Sengkol Wisata Pemancingan Keluarga di Serpong Tangerang Selatan. Metode yang digunakan adalah explanatory research dengan teknik analisis menggunakan analisis statistik dengan pengujian regresi, korelasi, determinasi dan uji hipotesis. Hasil penelitian ini disiplin kerja berpengaruh signifikan terhadap kinerja karyawan sebesar $42,6 \%$, uji hipotesis diperoleh $t$ hitung $>t$ tabel atau $(6,267>2,006)$. Motivasi berpengaruh signifikan terhadap kinerja karyawan sebesar $42,7 \%$, uji hipotesis diperoleh $t$ hitung $>\mathrm{t}$ tabel atau $(6,289>2,006)$. Disiplin kerja dan motivasi secara simultan berpengaruh signifikan terhadap kinerja karyawan dengan persamaan regresi $\mathrm{Y}=9,773+0,379 \mathrm{X} 1+$ $0,382 X 2$ dan kontribusi pengaruh sebesar $54,1 \%$, uji hipotesis diperoleh $\mathrm{F}$ hitung $>\mathrm{F}$ tabel atau $(30,636$ $>2,780$ ).
\end{abstract}

Kata Kunci: Disiplin Kerja, Motivasi, Kinerja Karyawan

\section{Abstract}

This study aims to determine the effect of work discipline and motivation on employee performance at Lubana Sengkol Family Fishing Tour in Serpong, South Tangerang. The method used is explanatory research with analytical techniques using statistical analysis with regression, correlation, determination and hypothesis testing. The results of this study that work discipline has a significant effect on employee performance by $42.6 \%$, hypothesis testing is obtained t count $>t$ table or $(6.267>2.006)$. Motivation has a significant effect on employee performance by $42.7 \%$, hypothesis testing is obtained $t$ count $>t$ table or $(6,289>2,006)$. Work discipline and motivation simultaneously have a significant effect on employee performance with the regression equation $Y=$ $9.773+0.379 X 1+0.382 X 2$ and the contribution of the effect is $54.1 \%$, hypothesis testing is obtained F count $>$ F table or $(30,636>2,780)$.

Keywords: Work Discipline, Motivation, Employee Performance

\section{PENDAHULUAN}

Pada era globalisasi saat ini, setiap organisasi atau perusahaan yang berbentuk pemerintah maupun swasta tentunya memiliki tujuan baik itu dalam jangka pendek maupun jangka panjang yang hendak dicapai melalui aktivitas yang dilakukan, agar tujuan yang telah ditetapkan dapat tercapai. Seraca umun, manajemen dipandang sebagai sebuah disiplin ilmu yang mengajarkan tentang proses untuk memperoleh tujuan organisasi. Manajemen yang baik akan memudahkan terwujudnya tujuan perusahaan, karyawan, dan masyarakat.

Menurut Hasibuan

(2016:9)
Manajemen diartikan sebagai ilmu dan seni mengatur proses pemanfaatan sumber daya manusia dan sumber-sumber daya lainnya secara efektif dan efisien untuk mencapai suatu tujuan tertentu. Untuk mencapai tujuan tersebut maka diperlukan perencanaan, dan pengelolaan sumber daya manusia sebaik-baiknya. Sumber daya manusia adalah yang terpenting dan sangat menentukan dari seluruh sumber daya yang tersedia dalam suatu organisasi pemerintah maupun swasta. Sumber daya manusia merupakan satu-satunya yang memiliki akal, perasaan, keinginan, kemampuan, keterampilan, pengetahuan, 
dorongan, daya dan karya. (Arif Yusuf Hamali 2018:3).

Disiplin kerja merupakan salah satu komponen yang turut menentukan baik buruknya kinerja seseorang. Karyawan yang disiplin dalam bekerja akan cenderung untuk melakukan segala aktivitasnya sesuai dengan tata aturan, standar maupun tugas dan tanggung jawab yang menjadi kewajibannya. Kepatuhan terhadap peraturan kerja yang telah ditetapkan oleh manajemen merupakan jaminan keberhasilan dalam pencapaian tujuan organisasi atau perusahaan.

Menurut Hasibuan (2016:193) "Kedisiplinan adalah kesadaran dan kesediaan seseorang menaati semua peraturan perusahaan dan norma-norma sosial yang berlaku". Disiplin yang baik mencerminkan besarnya rasa tanggung jawab seseorang terhadap tugas-tugas yang diberikan kepadanya. Hal ini mendorong gairah kerja, semangat kerja, dan terwujudnya tujuan perusahaan, karyawan, dan masyarakat.

Menurut Sastrohadiwiryo Siswanto dalam R. Supomo Eti Nurhayati (2018:133), disiplin kerja didefinisikan sebagai suatu sikap menghargai, menghormati, patuh, dan taat terhadap peraturan-peraturan yang berlaku baik secara tertulis maupun yang tidak tertulis serta sanggup menjalankan dan tidak mengelak untuk menerima sanksi-sanksi apabila melanggar tugas dan wewenang yang diberikan kepadanya.

Dalam mencapai hasil yang optimal perusahaan tidak hanya meningkatkan kedisiplinan namun perlu juga dalam memberikan motivasi, pemberian motivasi perlu dicermati secara sistematis perkembangannya dan juga memerlukan perhatian dari atasan perusahaan itu sendiri, sehingga dapat meningkatkan prilaku kerja karyawan. Motivasi dapat dikembangkan apabila timbul kebutuhan maupun tujuan baru. Apabila pemenuhan kebutuhan merupakan kepentingan manusia, maka tujuan dapat menjadi kepentingan manusia maupun organisasi.

Motivasi bertujuan untuk memacu karyawan agar lebih aktif dalam melaksanakan pekerjaan guna mencapai hasil yang optimal. Motivasi mempersoalkan bagaimana caranya mengarahkan daya dan potensi bawahan, agar mau bekerja sama secara produktif berhasil mencapai dan mewujudkan tujuan yang telah ditentukan. Pentingnya motivasi adalah karena motivasi adalah hal yang menyebabkan, menyalurkan, dan mendukung prilaku manusia, supaya mau bekerja giat dan antusias mencapai hasil yang optimal.

Menurut dalam Hasibuan (2016:145) bahwa "Motivasi adalah keinginan yang terdapat pada diri seseorang individu yang merangsangnya untuk melakukan tindakan-tindakan". Stefan Ivanko (2012:70) mendefinisikan "Motivasi sebagai keinginan dan energi seseorang yang diarahkan untuk pencapaian suatu tujuan". Apabila seorang pekerja mempunyai motivasi untuk mencapai tujuan pribadinya, maka mereka harus meningkatkan kinerja. Meningkatnya kinerja pekerja akan meningkatkan pula kinerja organisasi.

Kinerja yang baik dapat membantu perusahaan memperoleh keuntungan. Sebaliknya, bila kinerja menurun maka dapat merugikan perusahaan. Menurut Sedarmayanti $(2013 ; 260)$ "Kinerja adalah hasil kerja seorang pekerja, sebuah proses manajemen atau suatu organisasi secara keseluruhan, dimana hasil kerja tersebut harus dapat ditunjukan buktinya secara konkrit dan dapat diukur dibandingkan dengan standar yang telah ditentukan". Kinerja merupakan poin penting dalam kemajuan perusahaan, semakin meningkatnya kinerja karyawan maka akan semakin cepat tercapainya tujuan perusahaan tersebut. Semakin besar kinerja karyawan maka prestasi kinerja karyawan juga akan semakin cepat tercapai sehingga produktivitas dan tujuan perusahaan pun akan tercapai.

Lubana Sengkol merupakan tempat wisata yang didalamnya terdiri dari pondak makan, pemancingan, dan outbound. Lubana berada di Jl. Baru HK, KM 1,5 
Kampung Sengkol, Muncul, Tangerang Selatan. Dengan memberikan suasana alam yang hijau dan jauh dari kepadatan kota, Visi dan Misi perusahaan yaitu menjadikan Lubana Sengkol sebagai icon kota Tangerang selatan sebagai One Stop Adventure And Entertainment.

Dengan didasari niat baik ingi menjadikan Lubana Sengkol sebagai tempat yang dapat mengangkat derajat dan kehidupan orang-orang sekitar yang membutuhkan, Lubana Sengkol telah berkembang besar dan luas seperti saat ini. Lubana Sengkol menyadari bahwa untuk mewujudkan visi dan misinya sangat penting untuk memiliki sumber daya manusia yang berkualitas dan memiliki komitmen serta menjaga kualitas yang konsisten untuk mampu mendorong kinerja perusahaan. Oleh sebab itu perusahaan sangat mengharapkan karyawannya menciptakan disiplin kerja yang tinggi demi kemajuan perusahaan.

Berdasarkan latar belakang permasalahan diatas, maka penulis tertarik untuk melakukan penelitian lebih lanjut dengan judul "Pengaruh Disiplin Kerja dan Motivasi Terhadap Kinerja Karyawan Pada Lubana Sengkol Wisata Pemancingan Keluarga Serpong Tangerang Selatan".

\section{TINJAUAN PUSTAKA}

\section{Disiplin kerja}

Menurut

Sutrisno

mendefinisikan "Disiplin kerja adalah perilaku seseorang yang sesuai dengan peraturan, prosedur kerja yang ada atau sikap dan tingkah laku serta perbuatan yang sesuai dengan peraturan dari organisasi baik tertulis maupun tidak tertulis". Dalam penelitian ini indikator yang digunakan meliputi: taat terhadap aturan waktu taat terhadap aturan organisasi, taat terhadap aturan perilaku dalam pekerjaan, taat terhadap peraturan lainnya.

\section{Motivasi}

Yang dimaksud disiplin kerja dalam penelitian ini adalah kesadaran dan kesediaan seseorang menaati semua peraturan perusahaan dan normanorma sosial yang berlaku. (Hasibuan, 2014:193). Adapun indikator yang digunakan meliputi: tujuan dan kemampuan, teladan pimpinan, balas jasa, keadilan, dan ketegasan.

\section{Kinerja Karyawan}

Dalam penelitian ini yang dijadikan variabel dependen adalah kinerja karyawan yang diartikan sebagai hasil kerja seorang pekerja, sebuah proses manajemen atau suatu organisasi secara keseluruhan, dimana hasil kerja tersebut harus dapat ditunjukkan buktinya secara konkrit dan dapat diukur, dibandingkan dengan standar yang telah ditentukan. (Sedarmayanti, 2013:260). Adapun indikator yang digunakan meliputi: prestasi kerja, tanggung jawab, ketaatan, kejujuran, dan kerjasama.

\section{METODE}

Populasi dalam penelitian ini berjumlah 55 responden Lubana Sengkol Wisata Pemancingan Keluarga di Serpong Tangerang Selatan. Sampel dalam penelitian ini berjumlah 55 responden. Jenis penelitian yang dipakai adalah kuantitatif, dimana tujuannya adalah untuk mengetahui pengaruh antara variabel bebas terhadap variabel terikat baik parsial maupun simultan Dalam menganalisis data digunakan uji instrumen, uji asumsi klasik, regresi, koefisien korelasi, koefisien determinasi dan uji hipotesis.

\section{HASIL DAN PEMBAHASAN}

\section{Analisis Deskriptif}

Pada pengujian ini digunakan untuk mengetahui skor minimum dan maksimum, mean score dan standar deviasi dari masing-masing variabel. Adapun hasilnya sebagai berikut: 
Tabel 1. Hasil Analisis Descriptive Statistics

\begin{tabular}{lr|r|r|r|r} 
& N & \multicolumn{3}{c}{ Mescriptive Statistics } & \\
& 55 & 31 & 48 & 39.11 & 3.789 \\
\hline Disiplin Kerja (X1) & 55 & Maximum & Mean & Std. Deviation \\
\hline Motivasi (X2) & 55 & 30 & 46 & 38.65 & 3.792 \\
\hline Kinerja Karyawan (Y) & 55 & 31 & 46 & 39.36 & 3.482 \\
\hline Valid N (listwise) & 55 & & & & \\
\hline
\end{tabular}

Disiplin kerja diperoleh varians minimum sebesar 31 dan varians maximum 48 dengan mean score sebesar 39,11 dengan standar deviasi 3,789.

Motivasi diperoleh varians minimum sebesar 30 dan varians maximum 46 dengan mean score sebesar 38,65 dengan standar deviasi 3,792.

Kinerja karyawan diperoleh varians minimum sebesar 31 dan varians maximum 46 dengan mean score sebesar 39,36 dengan standar deviasi 3,482.
2. Analisis Kuantitatif

Pada analisis ini dimaksudkan untuk mengetahui pengaruh variabel independen terhadap variabel dependen. Adapun hasil pengujian sebagai berikut:

\section{a. Analisis Regresi Linier Berganda}

Uji regresi ini dimaksudkan untuk mengetahui perubahan variabel dependen jika variabel independen mengalami perubahan. Adapun hasil pengujiannya sebagai berikut:

Tabel 2. Hasil Pengujian Regresi Linier Berganda

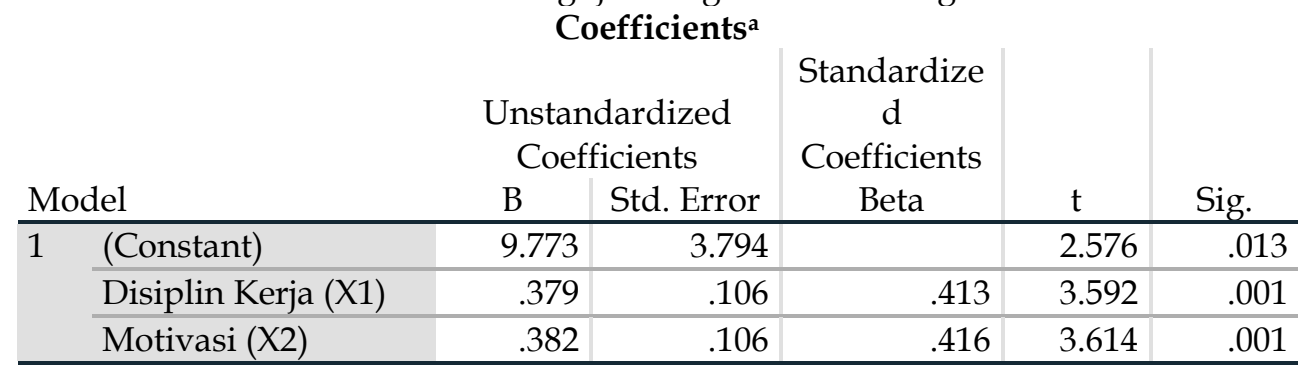

a. Dependent Variable: Kinerja Karyawan $(\mathrm{Y})$

Berdasarkan hasil pengujian pada tabel di atas, diperoleh persamaan regresi $Y=9,773+0,379 X 1$ $+0,382 X 2$. Dari persamaan tersebut dijelaskan sebagai berikut:

1) Konstanta sebesar 9,773 diartikan jika disiplin kerja dan motivasi tidak ada, maka telah terdapat nilai kinerja karyawan sebesar 9,773 point.

2) Koefisien regresi disiplin kerja sebesar 0,379, angka ini positif artinya setiap ada peningkatan disiplin kerja sebesar 0,379 maka kinerja karyawan juga akan mengalami peningkatan sebesar
0,379 point.

3) Koefisien regresi motivasi sebesar 0,382, angka ini positif artinya setiap ada peningkatan motivasi sebesar 0,382 maka kinerja karyawan juga akan mengalami peningkatan sebesar 0,382 point.

\section{b. Analisis Koefisien Korelasi}

Analisis koefisien korelasi dimaksudkan untuk mengetahui tingkt kekuatan hubungan dari variabel independen terhadap variabel dependen baik secara parsial maupun simultan. Adapun hasil pengujian sebagai berikut: 
Tabel 3. Hasil Pengujian Koefisien Korelasi Disiplin kerja Terhadap Kinerja Karyawan.

\section{Correlations $^{\mathrm{b}}$}

\begin{tabular}{llr|r} 
& & $\begin{array}{c}\text { Disiplin Kerja } \\
(\mathrm{X} 1)\end{array}$ & \multicolumn{1}{c}{$\begin{array}{c}\text { Kinerja } \\
\text { Karyawan (Y) }\end{array}$} \\
\hline Disiplin Kerja (X1) & Pearson Correlation & 1 & $.652^{* *}$ \\
\cline { 2 - 4 } & Sig. (2-tailed) & & .000 \\
\hline Kinerja Karyawan & Pearson Correlation & $.652^{* *}$ & 1 \\
\cline { 2 - 4 }$(\mathrm{Y})$ & Sig. (2-tailed) & .000 & \\
\hline
\end{tabular}

**. Correlation is significant at the 0.01 level (2-tailed).

b. Listwise $\mathrm{N}=55$

Berdasarkan hasil pengujian diperoleh nilai korelasi sebesar 0,652 artinya disiplin kerja memiliki hubungan yang kuat terhadap kinerja karyawan.

Tabel 4. Hasil Pengujian Koefisien Korelasi Motivasi Terhadap Kinerja Karyawan.

\begin{tabular}{llr|r} 
& \multicolumn{2}{c}{ Correlations $^{\mathbf{b}}$} & \multicolumn{2}{c}{$\begin{array}{c}\text { Kinerja } \\
\end{array}$} & Motivasi (X2) & \multicolumn{1}{c}{ Karyawan (Y) } \\
\hline Motivasi (X2) & Pearson Correlation & 1 & $.653^{\text {** }}$ \\
\cline { 2 - 4 } & Sig. (2-tailed) & & .000 \\
\hline Kinerja Karyawan (Y) & Pearson Correlation & $.653^{\text {** }}$ & 1 \\
\cline { 2 - 4 } & Sig. (2-tailed) & .000 & \\
\hline
\end{tabular}

**. Correlation is significant at the 0.01 level (2-tailed).

b. Listwise $\mathrm{N}=55$

Berdasarkan hasil pengujian diperoleh nilai korelasi sebesar 0,653

artinya motivasi memiliki hubungan

Tabel 5. Hasil Pengujian Koefisien Korelasi Disiplin kerja dan Motivasi secara simultan Terhadap Kinerja Karyawan.

Model Summary

\begin{tabular}{|c|c|c|c|c|}
\hline \multicolumn{5}{|c|}{ 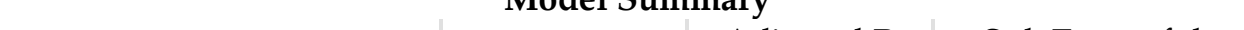 } \\
\hline Model & $\mathrm{R}$ & R Square & $\begin{array}{l}\text { Adjusted R } \\
\text { Square }\end{array}$ & $\begin{array}{l}\text { Std. Error of the } \\
\text { Estimate }\end{array}$ \\
\hline 1 & & .54 & .523 & 2.40 \\
\hline
\end{tabular}

a. Predictors: (Constant), Motivasi (X2), Disiplin Kerja (X1)

Berdasarkan hasil pengujian diperoleh nilai korelasi sebesar 0,735 artinya disiplin kerja dan motivasi secara simultan memiliki hubungan yang kuat terhadap kinerja karyawan.

\section{c. Analisis Koefisien Determinasi}

Analisis koefisien determinasi dimaksudkan untuk mengetahui besarnya persentase pengaruh dari variabel independen terhadap variabel dependen baik secara parsial maupun simultan. Adapun hasil pengujian sebagai berikut:

Tabel 6. Hasil Pengujian Koefisien Determinasi Disiplin kerja Terhadap Kinerja Karyawan.

\section{Model Summary}

\begin{tabular}{lr|r|r|rr} 
Model & $\mathrm{R}$ & \multicolumn{2}{c|}{$\begin{array}{c}\text { Adjusted R } \\
\text { R Square }\end{array}$} & \multicolumn{2}{c}{$\begin{array}{c}\text { Std. Error of the } \\
\text { Square }\end{array}$} \\
\hline 1 & $.652^{\mathrm{a}}$ & .426 & .415 & 2.664 \\
\hline
\end{tabular}

Berdasarkan hasil pengujian diperoleh nilai determinasi sebesar 0,426 artinya disiplin kerja memiliki kontribusi pengaruh sebesar $42,6 \%$ terhadap kinerja karyawan. 
Tabel 7. Hasil Pengujian Koefisien Determinasi Motivasi Terhadap Kinerja Karyawan.

Model Summary

\begin{tabular}{lr|r|r|rr} 
Model & $\mathrm{R}$ & R Square & $\begin{array}{c}\text { Adjusted R } \\
\text { Square }\end{array}$ & \multicolumn{2}{c}{$\begin{array}{c}\text { Std. Error of the } \\
\text { Estimate }\end{array}$} \\
\hline 1 & $.653^{a}$ & .427 & .416 & 2.661 \\
\hline a. Predictors: (Constant), Motivasi (X2) & & &
\end{tabular}

Berdasarkan hasil pengujian diperoleh nilai determinasi sebesar 0,427 artinya motivasi memiliki kontribusi pengaruh sebesar $42,7 \%$ Tabel 8. Hasil Pengujian Koefisien Determinasi Disiplin kerja dan Motivasi Terhadap Kinerja Karyawan.

Model Summary

\begin{tabular}{|c|c|c|c|c|}
\hline Model & $\mathrm{R}$ & R Square & $\begin{array}{l}\text { Adjusted R } \\
\text { Square }\end{array}$ & $\begin{array}{l}\text { Std. Error of the } \\
\text { Estimate }\end{array}$ \\
\hline 1 & $.735^{a}$ & .541 & .523 & 2.404 \\
\hline
\end{tabular}

a. Predictors: (Constant), Motivasi (X2), Disiplin Kerja (X1)

Berdasarkan hasil pengujian diperoleh nilai determinasi sebesar 0,541 artinya disiplin kerja dan motivasi secara simultan memiliki kontribusi pengaruh sebesar $54,1 \%$ terhadap kinerja karyawan, sedangkan sisanya sebesar $45,9 \%$ dipengaruhi faktor lain.

\section{d. Uji Hipotesis}

\section{Uji hipotesis Parsial (Uji $t$ )}

Pengujian hipotesis dengan uji $t$ digunakan untuk mengetahui hipotesis parsial mana yang diterima.

Hipotesis pertama: Terdapat pengaruh yang signifikan antara disiplin kerja terhadap kinerja karyawan.

Tabel 9. Hasil Uji Hipotesis Disiplin kerja Terhadap Kinerja Karyawan.

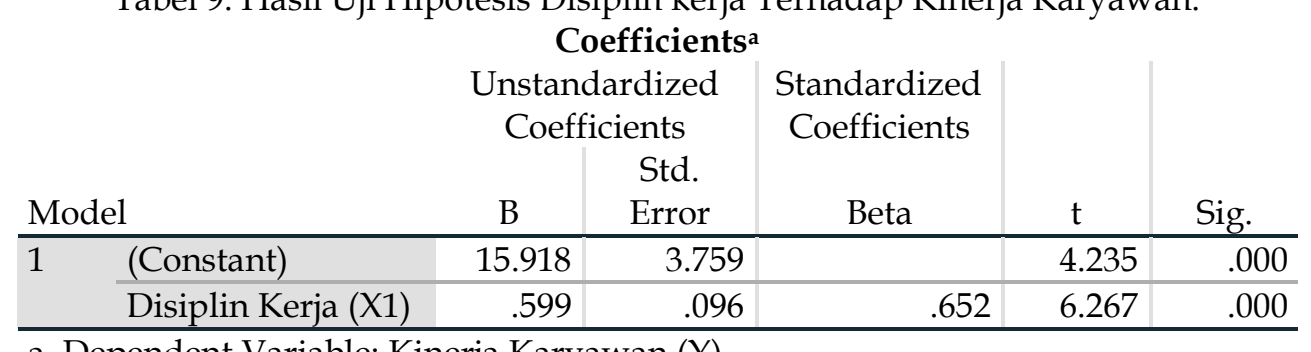

a. Dependent Variable: Kinerja Karyawan $(\mathrm{Y})$

Berdasarkan hasil pengujian pada tabel di atas, diperoleh nilai $\mathrm{t}$ hitung $>\mathrm{t}$ tabel atau $(6,267>2,006)$, dengan demikian hipotesis pertama yang diajukan bahwa terdapat pengaruh yang signifikan atara disiplin kerja terhadap kinerja karyawan diterima.

Tabel 10. Hasil Uji Hipotesis Motivasi Terhadap Kinerja Karyawan.

\begin{tabular}{|c|c|c|c|c|c|c|}
\hline \multirow{3}{*}{\multicolumn{2}{|c|}{ Model }} & & oefficients ${ }^{a}$ & \multirow{3}{*}{$\begin{array}{l}\text { Standardized } \\
\text { Coefficients } \\
\text { Beta }\end{array}$} & \multirow[b]{3}{*}{$\mathrm{t}$} & \multirow[b]{3}{*}{ Sig. } \\
\hline & & \multicolumn{2}{|c|}{$\begin{array}{l}\text { Unstandardized } \\
\text { Coefficients }\end{array}$} & & & \\
\hline & & B & Std. Error & & & \\
\hline & (Constant) & 16.169 & 3.708 & & 4.360 & .000 \\
\hline & Motivasi (X2) & .600 & .095 & .653 & 6.285 & .000 \\
\hline
\end{tabular}

a. Dependent Variable: Kinerja Karyawan (Y)

Berdasarkan hasil pengujian pada tabel di atas, diperoleh nilai $t$ hitung $>\mathrm{t}$ tabel atau $(6,289>2,006)$, dengan demikian hipotesis kedua yang diajukan bahwa terdapat pengaruh yang signifikan atara 
motivasi terhadap kinerja karyawan diterima.

\section{Uji Hipotesis Simultan (Uji F)}

Pengujian hipotesis dengan uji $\mathrm{F}$ digunakan untuk mengetahui hipotesis simultan yang mana yang diterima.

Hipotesis ketiga Terdapat pengaruh yang signifikan antara disiplin kerja dan motivasi terhadap kinerja karyawan.

Tabel 11. Hasil Uji Hipotesis Disiplin kerja dan Motivasi Terhadap Kinerja Karyawan.

ANOVA $^{\mathrm{a}}$

\begin{tabular}{ll|r|r|r|c|c} 
Model & & Sum of Squares & df & Mean Square & F & Sig. \\
\hline \multirow{2}{*}{1} & Regression & 354.162 & 2 & 177.081 & 30.636 & $.000^{\mathrm{b}}$ \\
\cline { 2 - 8 } & Residual & 300.565 & 52 & 5.780 & & \\
\cline { 2 - 8 } & Total & 654.727 & 54 & & & \\
\hline
\end{tabular}

a. Dependent Variable: Kinerja Karyawan $(\mathrm{Y})$

b. Predictors: (Constant), Motivasi (X2), Disiplin Kerja (X1)

Berdasarkan hasil pengujian pada tabel di atas, diperoleh nilai $\mathrm{F}$ hitung > F tabel atau $(30,636>2,780)$, dengan demikian hipotesis ketiga yang diajukan bahwa terdapat pengaruh yang signifikan atara disiplin kerja dan motivasi terhadap kinerja karyawan diterima.

\section{PEMBAHASAN HASIL PENELITIAN}

1. Pengaruh Disiplin kerja Terhadap Kinerja Karyawan

Disiplin kerja berpengaruh signifikan terhadap kinerja karyawan dengan korelasi sebesar 0,652 atau memiliki hubungan yang kuat dengan kontribusi pengaruh sebesar 42,6\%. Pengujian hipotesis diperoleh nilai $t$ hitung $>\mathrm{t}$ tabel atau $(6,267>2,006)$. Dengan demikian hipotesis pertama yang diajukan bahwa terdapat berpengaruh signifikan antara disiplin kerja terhadap kinerja karyawan diterima.

\section{Pengaruh Motivasi Terhadap Kinerja Karyawan}

Motivasi berpengaruh signifikan terhadap kinerja karyawan dengan korelasi sebesar 0,653 atau memiliki hubungan yang kuat dengan kontribusi pengaruh sebesar $42,7 \%$. Pengujian hipotesis diperoleh nilai $\mathrm{t}$ hitung $>\mathrm{t}$ tabel atau $(6,289>2,006)$. Dengan demikian hipotesis kedua yang diajukan bahwa terdapat berpengaruh signifikan antara motivasi terhadap kinerja karyawan diterima.

\section{Pengaruh Disiplin kerja dan Motivasi} Terhadap Kinerja Karyawan

Disiplin kerja dan motivasi berpengaruh signifikan terhadap kinerja karyawan dengan diperoleh persamaan regresi $\mathrm{Y}=9,773+0,379 \mathrm{X} 1+0,382 \mathrm{X} 2$, nilai korelasi sebesar 0,735 atau memiliki hubungan yang kuat dengan kontribusi pengaruh sebesar $54,1 \%$ sedangkan sisanya sebesar $45,9 \%$ dipengaruhi faktor lain. Pengujian hipotesis diperoleh nilai $\mathrm{F}$ hitung > F tabel atau $(30,636>2,780)$. Dengan demikian hipotesis ketiga yang diajukan bahwa terdapat berpengaruh signifikan antara disiplin kerja dan motivasi terhadap kinerja karyawan diterima.

\section{PENUTUP}

\section{Kesimpulan}

1. Disiplin kerja berpengaruh signifikan terhadap kinerja karyawan dengan kontribusi pengaruh sebesar $42,6 \%$. Uji hipotesis diperoleh nilai thitung $>\mathrm{t}$ tabel atau $(6,267>2,006)$.

2. Motivasi berpengaruh signifikan terhadap kinerja karyawan dengan kontribusi pengaruh sebesar $42,7 \%$. Uji hipotesis diperoleh nilai thitung $>\mathrm{t}$ tabel atau $(6,289>2,006)$.

3. Disiplin kerja dan motivasi berpengaruh signifikan terhadap kinerja karyawan dengan kontribusi pengaruh sebesar 
$54,1 \%$ sedangkan sisanya sebesar $45,9 \%$ dipengaruhi faktor lain. Uji hipotesis diperoleh nilai $\mathrm{F}$ hitung $>\mathrm{F}$ tabel atau $(30,636>2,780)$.

\section{Saran}

1. Perusahaan harus melakukan peningkatan teladan seorang pemimpin yang baik, seorang pimpinan yang mampu menginspirasi karyawannya, sehingga karyawan dapat mencontoh hal-hal yang baik atau positif.

2. Perusahaan harus memperhatikan lingkungan sosial tempat kerja, menjamin perusahaan memiliki lingkungan kerja yang nyaman, agar karyawan merasa betah bekerja diperusahaan, dan merasa dirinya berada disekeliling orang-orang yang dapat menerimanya serta menghargai dirinya.

3. Perusahaan harus melakukan pengawasan terhadap kinerja karyawan agar tugas dan tanggung jawab yang telah diberikan dapat dijalankan dengan maksimal, agar karyawan tidak memperlambat penyelesaian tugas yang telah diberikan.

4. Kontribusi pengaruh antara disiplin kerja dan motivasi secara simultan terhadap kinerja karyawan sebesar $54,1 \%$, nilai ini masih bisa ditingkatkan dengan memprioritaskan karyawan dan kondisi masing-masing variabel bebas harus ditingkatkan secara signifikan. Oleh karenanya disarankan kepada penelitian berikutnya agar melakukan penelitian yang relevan dengan cara memperbaiki indikator yang masih tidak baik atau dengan menambah indikator pernyataan dan jumlah responden penelitian sehingga akan dapat lebih diketahui variabel yang paling memberikan kontribusi positif bagi perusahaan.

\section{DAFTAR PUSTAKA}

A. A. Anwar Prabu Mangkunegara, "Manajemen Sumber Daya Manusia". PT. Remaja Rosdakarya, Bandung, 2010.
Algifari, "Analisis Regresi". Yogyakarta, 2011.

Andi Supangat, "Statistika dalam Kajian Deskriftif, Inferensi dan Non Parametric", Edisi Pertama, Kencana Prenada Media Group, Jakarta, 2014.

Arikunto, Suharsimi, "Prosedur Penelitian Suatu Pendekatan Praktek". PT. Rineka Cipta, Jakarta, 2015.

Bangun, Wilson, "Manajemen Sumber Daya Manusia". Erlangga, Jakarta, 2012.

Ghozali, Imam, "Aplikasi Analisis Multivariate dengan Program SPSS". BadanPenerbit Undip, Semarang, 2014.

Hamali, Arif Yusuf, "Pemahaman Manajemen Sumber Daya Manusia". CAP (Center For Academic Publishing Service), Yogyakarta, 2018. Handoko, "Manajemen Personalia dan Sumber Daya Manusia". BPFE UGM, Yogyakarta, 2011.

Hasibuan, Malayu S.P, "Manajemen Sumber Daya Manusia". PT. Bumi Aksara, Jakarta, 2014.

Hayati, F. A., \& Susetyo, E. (2020). Hubungan Komunikasi Terhadap Kinerja Karyawan Pada PKBM Insan Karya Tangerang Selatan. JENIUS (Jurnal Ilmiah Manajemen Sumber Daya Manusia), 3(2), 140-147.

Istijanto, "Aplikasi Praktis Riset Pemasaran". Gramedia Pustaka Utama, Jakarta, 2012

Kristianti, L. S., Affandi, A., Nurjaya, N., Sunarsi, D., \& Rozi, A. (2021). Pengaruh Motivasi Dan Disiplin Kerja Terhadap Kinerja Pegawai Pada Dinas Pariwisata Purwakarta. Jurnal Ilmiah PERKUSI, 1(1), 101-109.

Nurjaya, N., Affandi, A., Ilham, D., Jasmani, J., \& Sunarsi, D. (2021). Pengaruh Kompetensi Sumber Daya Manusia Dan Kemampuan Pemanfaatan Teknologi Terhadap Kinerja Aparatur Desa Pada Kantor Kepala Desa Di Kabupaten Gunungkidul, Yogyakarta. JENIUS (Jurnal Ilmiah Manajemen Sumber Daya Manusia), 4(3), 332-346. 
Oktavianti, N. (2020). Pengaruh Motivasi dan Kepuasan Kerja terhadap Kinerja Kerja Karyawan PT. DEW Indonesia. JENIUS (Jurnal Ilmiah Manajemen Sumber Daya Manusia), 3(2), 148-155.

Paramarta, V., Dewi, R. R. V. K., Rahmanita, F., Hidayati, S., \& Sunarsi, D. (2021). Halal Tourism in Indonesia: Regional Regulation and Indonesian Ulama Council Perspective. International Journal of Criminology and Sociology, 10, 497-505.

Rialmi, Z. (2020). Pengaruh Kedisiplinan Terhadap Kinerja Karyawan Pada PT. Bhakti Karya Distribusi Indonesia. JENIUS (Jurnal Ilmiah Manajemen Sumber Daya Manusia), 3(3), 286-293.

Rivai, Veithzal dan Ella Sagala, "Manajemen Sumber Daya Manusia untuk Perusahaan". Rajawali Pers, Jakarta, 2013.

Santoso, Singgih, "SPSS Statistik Parametik". Cetakan Kedua, PT. Elek Media, 2015.

Sedarmayanti, "Manajemen Sumber Daya Manusia". Refika Aditama, Bandung, 2013.
Simamora, Hendry, "Manajemen Sumber Daya Manusia". Sekolah Tinggi Ilmu Ekonomi YKPN, Yogyakarta, 2014.

Simanjuntak, Payaman, "Manajemen dan Evaluasi Kinerja". Fakultas Ekonomi UI, Jakarta, 2011.

Sinabela, Lithen Poltak, "Manajemen Sumber Daya Manusia". Cetakan kesatu, PT. Bumi Aksara, Jakarta, 2016

Sudjana, "Metode Statistika", Edisi Keenam, Tarsito, Bandung, 2011.

Sugiyono, "Metode Penelitian Kuantitatif Kualitatif dan R \& D", Penerbit CV. Alfabeta, Bandung, 2016.

Supomo, R dan Eti Nurhayati, "Manajemen Sumber Daya Manusia". YramaWidya, Bandung, 2018.

Sutrisno, Edy, "Manajemen Sumber Daya Manusia". Prenada Media Group, Jakarta, 2014.

Terry, George R \& Rue, Leslie W. Rue, "Dasar-Dasar Manajemen". Jakarta Bumi Aksara, Jakarta, 2010.

Wibowo, "Manajemen Kinerja". PT. Raja Grafindo Persada, Depok, 2017. 